\title{
INOVASI RUMAH SEHAT LANSIA OLEH DINAS KESEHATAN KOTA YOGYAKARTA DALAM MEWUJUDKAN LANSIA YANG PRODUKTIF
}

\author{
I Dewa Ayu Putri Wirantari \\ Pogram Studi Ilmu Administrasi Negara \\ Fakultas Ilmu Sosial dan Ilmu Politik \\ Email : putriwirantari@unud.ac.id
}

\begin{abstract}
ABSTRAK
Penduduk di Indonesia saat ini mengalami pertumbuhan yang cepat, terlebih lagi dewasa ini Indonesia mengalami fenomena peningkatan jumlah lansia yang begitu besar atau yang dapat kita kenal dengan ledakan penduduk usia lanjut, Angka pertumbuhan lansia terus meningkat setiap tahun. Menurut data Bappenas yang dikelola oleh Chandra menyatakan bahwa pada tahun 1980, penduduk lanjut usia baru berjumlah 7,7 juta jiwa atau 5,2\% dari total jumlah penduduk. Inovasi yang dilakukan oleh Dinas Kesehatan Kota Yogyakarta sedikit memberikan angin segar bagi efektivitas pelayanan kesehatan khususnya para lansia di kota Yogyakarta. Mengingat bahwa kota Yogyakarta merupakan kota dengan jumlah penduduk lansia terbanyak di Indonesia. Pemerintah kota Yogyakarta dan Dinas Kesehatan telah melakukan kerjasama yang baik dengan berbagai pihak sehingga berdirilah rumah sehat lansia yang beralamatkan di jalan Pakel Baru, Sorosutan Umbulharjo-Yogyakarta, didirikan pada tahun 2013 dan sudah beroperasi hingga sekarang. Bahkan inovasi Rumah Sehat Lansia ini telah masuk dalam 33 inovasi pelayanan terbaik oleh Kementerian Pendayagunaan Aparatur Negara (Kemenpan). Pemerintah kota Yogyakarta hendaknya memperhatikan fasilitas-fasilitas kesehatan mislanya peralatan medis, kamar dan tempat tidur pasien sehingga rumah sehat lansia dapat menampung pasien untuk menjalani rawat inap demi pelayanan kesehatan yang berkualitas. Memperhatikan jumlah tenaga medis dokter dan perawat yang menangani para lansia. Mengingat selama ini kunjungan dokter efektifnya hanya 2 kali dalam seminggu yakni hari rabu dan sabtu. Sehingga dengan jumlah dokter yang memadai maka jumlah kunjungan dokter dapat diperbanyak lagi bahkan diharapkan dapat melayani setiap hari mengingat jumlah pasien yang tidak sedikit.
\end{abstract}

Keyword : Inovasi, DIY, Lansia, Pelayanan Kesehatan.

\begin{abstract}
The population in Indonesia is currently increasing rapid growth, again nowadays Indonesia is experiencing the phenomenon of an increase in the number of elderly people who can be bigger than we can grow rapidly, the growth rate of the elderly continues to grow every year. According to data from Bappenas managed by Chandra, in 1980, the elderly population was only 7.7 million or $5.2 \%$ of the total population. The innovation carried out by the Yogyakarta City Health Office gives a little fresh air to the health care needs of the elderly in the city of Yogyakarta. Given the city of Yogyakarta is the city with the largest number of elderly population in Indonesia. The Yogyakarta city government and the Health Office have made good cooperation with the relevant parties to stand up for a healthy elderly house addressing Jalan Pakel Baru, Sorosutan Umbulharjo-Yogyakarta, established in 2013 and now available. Actually the innovation of the Elderly Healthy House has been included in the 33 best service innovations by the Ministry of Administrative Reform (Kemenpan). The Yogyakarta city government pays attention to health facilities such as medical equipment, rooms and patient beds so that elderly healthy homes can accommodate patients to increase hospitalization in accordance with quality health services. Noting the number of medical personnel and nurses who add to the elderly. It is hoped that during the doctor's visit it will be effective only 2 times a week, Wednesday and Saturday. The recommended amount that can be received every day
\end{abstract}

Keyword: DIY, Elderly, Innovation 


\section{PENDAHULUAN}

Penduduk di Indonesia saat ini mengalami pertumbuhan yang cepat, terlebih lagi dewasa ini Indonesia mengalami fenomena peningkatan jumlah lansia yang begitu besar atau yang dapat kita kenal dengan ledakan penduduk usia lanjut. Peningkatan jumlah lansia ini sejalan dengan peningkatan usia harapan hidup yang dikarenakan keberhasilan pemerintah dalam Pembangunan Nasional terutama dalam bidang medis atau ilmu kedokteran sehingga mampu meningkatkan kualitas kesehatan penduduk Indonesia serta dalam meningkatkan umur harapan hidup penduduk. Akibatnya jumlah penduduk yang berusia lanjut meningkat dan bertambah cenderung lebih cepat. Angka pertumbuhan lansia terus meningkat setiap tahun. Menurut data Bappenas yang dikelola oleh Chandra menyatakan bahwa pada tahun 1980, penduduk lanjut usia baru berjumlah 7,7 juta jiwa atau 10\% dari total jumlah penduduk. Pada tahun 1990, jumlah penduduk lansia meningkat menjadi 11,3 juta orang atau 25\%. Jumlah ini meningkat di seluruh Indonesia menjadi 15,1 juta jiwa pada tahun 2000 atau 25\% dari total keseluruhan jumlah penduduk. Diperkirakan pada tahun 2020, jumlah lansia akan meningkat menjadi 29 juta orang atau 40\%. Data ini menunjukkan bahwa penduduk lasia terus mengalami progresivitas dari waktu ke waktu.

\section{JUMLAH PENDUDUK LANSIA}

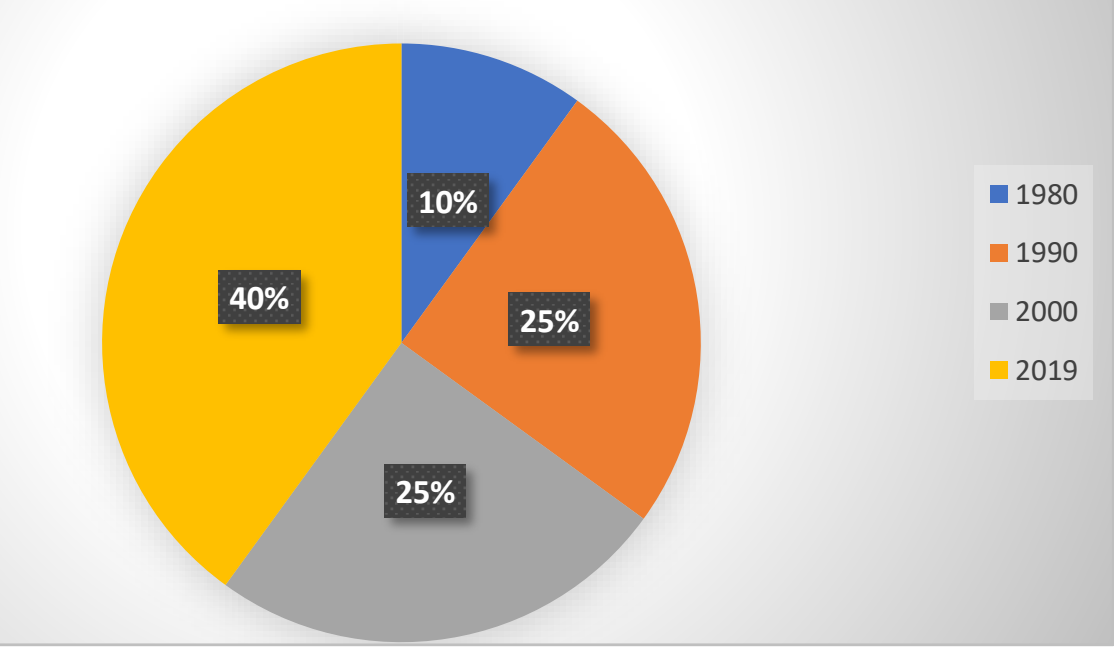


Jumlah penduduk lansia pada tahun 2000 mencapai 14,4 juta jiwa atau 7,18\% dari total jumlah penduduk. Pada tahun 2020 diperkirakan menjadi 28,9 juta atau naik menjadi 11,11\%, meningkat dua kali lipat dalam dua dekade. WHO telah memperhitungkan pada tahun 2025 Indonesia akan mengalami peningkatan jumlah lansia sebesar 41,4\% yang merupakan peningkatan tertinggi di dunia. Sehingga pemerintah mengharapkan Kota Ramah Lansia (AgeFriendly City) harus segera diwujudkan di Indonesia, mengingat kembali bahwa sampai saat ini di Indonesia belum ada kota yang benar-benar mampu menjadi kota ramah lansia. Program percepatan kota ramah lansia pada tujuannya merupakan salah satu upaya dalam mengantisipasi ledakan lansia di Indonesia tahun 2035. Selain itu, ledakan tersebut bisa menjadi beban sosial-ekonomi negara sehingga untuk mengantisipasi hal tersebut lansia perlu diberi aktivitas sehingga menjadi produktif ${ }^{1}$. Namun demikian, belum seluruh provinsi Indonesia berstruktur penduduk tua. Kondisi tersebut dapat dilihat dalam Gambar 3.3. Terlihat bahwa yang diarsir gelap (area dengan proporsi lansia lebih dari tujuh persen) hanya delapan provinsi. Artinya bahwa hanya 24,24 persen provinsi Indonesia yang memiliki struktur penduduk tua. Tiga provinsi dengan proporsi lansia terbesar adalah DI Yogyakarta (13,05 persen), Jawa Tengah (11,11 persen), Jawa Timur (10,96 persen), dan Bali (10,05 persen). Sementara itu, tiga provinsi dengan proporsi lansia terkecil adalah Papua (2,43persen), Papua Barat (3,62 persen), dan Kepulauan Riau (3,75 persen). ${ }^{2}$

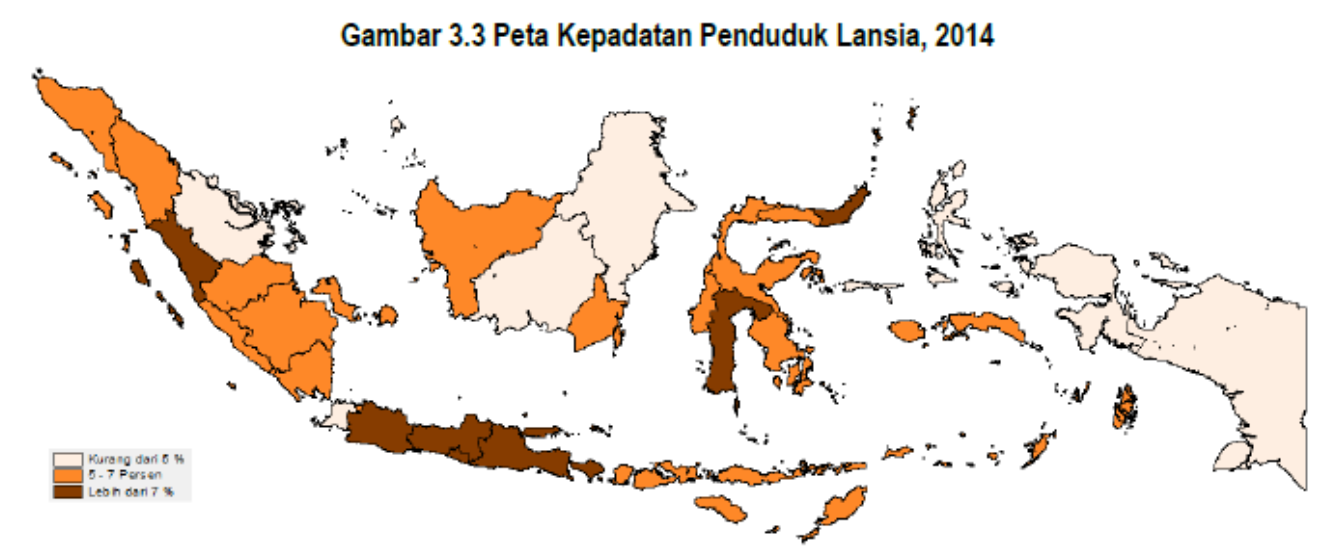

Sumber: BPS, Susenas 2014

Istiana.nodate.Kota Ramah Lanjut Usia.diakses pada tanggal 4 Juni 2016 melaui

http://eprints.uny.ac.id/20570/1/MAKALAH\%20KOTA\%20RAMAH\%20LANJUT\%20USIA.UNY.ISTIANA.pdf. 
Berdasarkan data diatas, diketahui bahwa Yogyakarta merupakan provinsi dengan penduduk lansia terbanyak di Indonesia. Setiap Lansia tentunya memiliki berbagai kondisi dan permasalahan khusus yang berbeda dengan penduduk pada usia lainnya, sehingga membutuhkan penanganan yang khusus pula didalam menghadapi para lansia ini. Berbicara mengenai lansia, tidak saja serta-merta hanya terkait dengan masalah kesehatan, namun juga berbagai kebutuhan lainnya, seperti berbagai fasilitas penunjang aktivitas lansia, kebutuhan lingkungan baik secara fisik maupun secara psikologi yang mampu membuat rasa nyaman bagi para lansia.

Berdasarkan data yang telah dipaparkan diatas, nampaknya belum ada kota di Indonesia yang sudah benar-benar menerapkan "Kota Ramah Lansia”.Adapun Pemkot Yogyakarta sendiri telah mulai berusaha untuk melakukan penyediaan pelayanan publik secara khusus bagi para lansia di kota Yogyakarta. Hal ini dapat kita lihat dari munculnya inovasi "Rumah Sehat Lansia" sebagai salah satu program kesehatan dari Dinas Kesehatan Kota Yogyakarta. Inovasi ini sendiri bergerak dalam bidang pelayanan kesehatan secara gratis bagi para lansia, dengan bekerjasama dengan Rumah Sakit Sardjito dan beberapa dokter ahli dalam untuk memberikan pelayanan yang lebih maksimal kepada masyarakat, khususnya masyarakat lansia. Peneliti tertarik untuk mengetahui secara mendalam tentang inovasi Rumah Sehat Lansia ini dan sejauhmana proses pelaksanaannya dalam memberikan pelayanan publik yang sesuai bagi para lansia di Kota Yogyakarta. Apalagi Yogyakarta merupakan provinsi dengan penduduk lansia terbanyak di Indonesia.

Berdasarkan pada latar belakang permasalahan diatas, maka penulis akan mencoba menjawab problematika yang ada melalui beberapa rumusan masalah, antara lain:

1. Bagaiman proses pengembangan inovasi Rumah Sehat Lansia yang digagas oleh Dinas Kesehatan Kota Yogyakarta?

2. Bagaimana analisis kandungan nilai yang terdapat pada Inovasi Rumah Sehat Lansia? 


\section{TUJUAN DAN MANFAAT}

Adapun tujuan dari penelitian ini adalah untuk mengetahui sejauh apa usaha pemerintah Kota Yogyakarta didalam menyesuaikan ledakan populasi lanjut usia di kota Yogyakarta, serta program kebijakan seperti apa yang dikeluarkan untuk menangani ledakan populasi lansia ini.

Manfaat penelitian ini dapat dilihat dari dua segi, antara lain (a) Manfaat akademis. Memberikan sumbangsih didalam ide dan pemikiran, tidak saja secara teoritik bagi pengembangan ilmu administrasi publik, namun juga secara empirik terkait dengan tata laksana pemerintahan terutama didalam melakukan pelayanan publik. (b) Manfaat praktis Memberikan tambahan wawasan dan pengetahuan bagi para pembaca mengenai pelaksanaan pelayanan publik oleh pemerintah Kota Yogyakarta kepada para lansia di Kota Yogyakarta.

\section{TINJAUAN PUSTAKA}

Pada bab ini, penulis akan mencoba untuk menganalisis inovasi "Rumah Sehat Lansia" dengan didasarkan kepada nilai-nilai yang terkandung didalamnya. Untuk itu, digunakan tiga indikator nilai untuk melihat inovasi tersebut, diantaranya: Value Proposition, Value Creation, dan Value Capture.

\section{Value/ Nilai}

Value/Nilai sosial yang tercipta dan terkandung didalam organisasi dapat dibagi menjadi 3, antara lain:

\section{a. Value Preposition}

Value Preposition secara singkat menggambarkan nilai yang diberikan organisasi kepada pelanggan dan kebutuhan pelanggan yang telah dipenuhi oleh organisasi.

Menurut Osterwalder dan Pigneur didalam Kusumasari, dkk (2015) ${ }^{3}$, proposisi nilai

"mengarah pada produk dan jasa yang menghasilkan nilai untuk segmen yang disasar oleh suatu organisasi, seperti newness, performance, dan customization; kemudian membantu pelanggan memenuhi kebutuhan, memiliki desain produk yang bernilai lebih, memiliki status, harga terjangkau dan adanya pengurangan harga, serta minimnya resiko

\footnotetext{
${ }^{3}$ Kutipan diambil dari : Kusumasari, dkk. 2015. Memahami Model Bisnis Organisasi Sosial di Indonesia. Yogyakarta: GAVA MEDIA, halaman 16
} 
dan kemudahan didalam aksesbilitas dalam menggunakan produk dan jasa suatu organisasi.",

Sedangkan Skok dalam Kusumasari $(2015)^{4}$ menyatakan bahwa proposisi nilai

“merupakan pernyataan mengenai keuntungan yang akan ditawarkan kepada pelanggan serta cara organisasi melakukan penawaran ini dengan baik dan unik, dimana hal ini terkait dengan yang menjadi target konsumen, masalah yang coba dijawab, dan keunggulan produk dibanding organisasi lain melalui beberapa tahapan, antara lain: pendefinisian masalah, evaluasi pada solusi yang ditawarkan, pengukuran tanggapan konsumen pada produk dan membangun proposisi nilai dari kebaruan dan kapabilitas produk".

\section{b. Value Creation (Nilai Penciptaan)}

Value Creation merupakan konsep finansial yang mengekspresikan kemampuan sebuah entitas ekonomi (organisasi, unit, bisnis) dalam bentuk kuantitatif. Dalam menciptakan nilai (value creation), memerlukan identifikasi yang jelas terhadap segmen pelanggan yang didasar pada suatu organisasi, proposisi nilai yang ada, serta cara organisasi menciptakan nilai bagi pengguna produk/jasanya; (Chesbrough \& Rosenbloom dalam Kusumasari; 2002). Karenanya nilai harus menciptakan nilai yang lebih atas produk/jasa. Keunikan merupakan salah satu nilai agar dapat berkompetisi dengan organisasi yang lain.

Lebih jauh lagi, Hax dalam Kusumasari (2002) menyatakan bahwa penciptaan nilai muncul apabila keuntungan yang diperoleh perusahaan mampu melebihi modal yang telah dikeluarkannya. Untuk itu organisasi perlu mengalokasikan sumber dayanya secara efektif. Dengan kata lain bahwa penciptaan nilai merupakan penciptaan suatu manfaat yang mempunyai harga tambah bagi organisasi.

\section{c. Value Capture (Tangkapan Nilai)}

Dalam mewujudkan tangkapan tangkapan nilai, maka organisasi harus mampu mengantarkan sebuah nilai pada pelanggannya. Nilai dapat ditujukan pada masyarakat (public value) maupun swasta (private value). (Moore dalam Kusumasari; 2002). Nilai

\footnotetext{
${ }^{4}$-ibid-
} 
yang dihasilkan oleh sektor privat erat kaitannya dengan keuntungan finansial, sedangkan nilai yang dihasilkan oleh sektor publik lebih mengarah pada kepentingan warganya.

\section{Analisis Nilai}

\section{a. Value Proposition}

Adapun indikator didalam value preposition ini dapat dilihat dari beberapa hal, antara lain:

\section{Latar Belakang Inovasi:}

- Adanya angka harapan hidup yang tinggi di kota Yogyakarta (rata-rata 74,2 tahun), sehingga menyebabkan ledakan penduduk lanjut usia. Bahkan Yogyakarta merupakan daerah dengan lansia tertinggi di Indonesia.

- Adanya kebutuhan untuk mewadahi kepentingan lansia

\section{Tujuan Inovasi:}

- Memberikan pelayanan, baik kesehatan prima maupun penyediaan lingkungan yang nyaman kepada para lansia

- Meningkatkan kualitas hidup para lansia agar lebih mandiri

\section{Isu Sosial :}

- Adanya ledakan penduduk lanjut usia yang mengalami progresitas setiap tahun

- Adanya kebutuhan agar penduduk usia lansia ini dapat lebih mandiri dan berdaya

\section{Pengguna Jasa dalam Inovasi Rumah Sehat Lansia}

- Pelanggan atau pengguna jasa organisasi ini umumnya adalah masyarakat yang dikategorikan sebagai penduduk lanjut usia dengan usia yang berkisar antara 45-60 tahun.

- Produk dan Jasa yang ditawarkan tidak semata-mata hanya pelayanan kesehatan terhadap lansia, namun juga pelayanan psikologis dan penciptaan lingkungan yang nyaman bagi para lansia

\section{b. Value Creation}

Adapun indikator didalam Value Creation antara lain:

\section{Aktivitas Program:}

- Melakukan terapi, bimbingan psikologi, cek kesehatan, pendeteksian penyakit degenaratif, dan sebagainya kepada lansia 


\section{Cara Kerja Program :}

- Melakukan sosialisasi tentang adanya program cek gratis kesehatan di rumah sehat lansia, yang tidak memandang KTP kepada tokoh-tokoh masyarakat maupun para pasien, sehingga dari mereka nanti, diharapkan turut menyebarkan tentang adanya Program Rumah Sehat Lansia, agar kedepannya, makin banyak lansia yang mendapatkan pelayanan dan manfaat dari program dinas kesehatan ini

- Menggandeng tenaga dokter spesialis penyakit dalam dari rumah sakit Sardjito, serta turut mengikutsertakan tenaga ahli Gayatri (ahli lansia) sebagai terapis, demi memberikan pelayanan yang lebih maksimal bagi para lansia, dan semua tenaga medis ini murni bergabung secara sukarela tanpa bayaran sepeserpun.

\section{Keberlanjutan Program :}

- Dinas Kesehatan akan terus mengembangkan inovasi Rumah Sehat ini, sehingga nantinya, tidak menyasar kepada lansia saja, namun juga pada usia lainnya sejak umur lima belas tahun. Sehingga program inovasi rumah sehat ini akan berguna sebagai medikal cek up yang berguna untuk mendeteksi penyakit sedini mungkin, agar dapat segera ditangani. Dengan demikian, kesehatan masyarakat akan semakin bagus dan angka harapan hidup semakin meningkat

\section{Pembiayaan :}

- Pembiayaan program ini 100\% dibiayai oleh dinas kesehatan, dimana setiap tahunnya, dinas kesehatan mengeluarkan dana sekitar Rp 312.000.000,- untuk membiayai program Rumah Sehat Lansia ini.

\section{c. Value Capture}

Adapun indikator yang terdapat pada Tangkapan nilai ini antara lain:

\section{Cara Mendapatkan Keuntungan}

- Program ini murni merupakan program yang bersifat non-profit yang tujuan utamanya memberikan pelayanan kesehatan secara gratis kepada para Lansia di kota Yogyakarta 


\section{Indikator Sukses:}

- Semakin banyak lansia yang mudah mendapatkan akses pelayanan kesehatan yang memadai melalui program inovasi ini, maka semakin sukses program ini.

- Sukses bagi Rumah Sakit Lansia adalah jika masyarakat secara umum dan lansia secara khusus memiliki tingkat kesehatan yang bagus serta memiliki angka harapan hidup yang tinggi. Selain itu, lansia juga dapat mandiri dan berdaya.

\section{Hambatan :}

- Masih terbatasnya dana

- Kurang Memadainya bangunan lokasi Rumah Sehat Lansia yang dinilai masih terlalu sempit, serta masih sangat terbatasnya unit Rumah Sehat Lansia yang sampai saat ini masih berjumlah satu buah unit.

\section{SIMPULAN}

Peningkatkan pelayanan publik yang berkualitas, pemerintah akan selalu melakukan inovasi, sehingga dengan pelayanan publik berkualitas pemerintah dapat mempertahankan para pelanggannya dalam hal ini masyarakat. Sebaliknya apabila organisasi pemerintahan tidak mampu melakukan inovasi dan bersaing dengan perusahaan lainnya maka akan banyak perusahaan yang berlomba-lomba menawarkan pelayanan yang berkualitas dan yang lebih efisien.Inovasi yang dilakukan oleh Dinas Kesehatan Kota Yogyakarta sedikit memberikan angin segar bagi efektivitas pelayanan kesehatan khususnya para lansia di kota Yogyakarta. Mengingat bahwa kota Yogyakarta merupakan kota dengan jumlah penduduk lansia terbanyak di Indonesia. Pemerintah kota Yogyakarta dan Dinas Kesehatan telah melakukan kerjasama yang baik dengan berbagai pihak sehingga berdirilah rumah sehat lansia yang beralamatkan di jalan Pakel Baru, Sorosutan Umbulharjo-Yogyakarta, didirikan pada tahun 2013 dan sudah beroperasi hingga sekarang. Bahkan inovasi Rumah Sehat Lansia ini telah masuk dalam 33 inovasi pelayanan terbaik oleh Kementerian Pendayagunaan Aparatur Negara (Kemenpan).

Pelayanan yang diberikan kepada masyarakat lansia berupa penanganan penyakit dalam dan pemeriksaan kesehatan seperti pengukuran tekanan darah, terapi dan screening serta layanan konsultasi. Pelayanan ini bersifat gratis tidak dipungut biaya apapun. Tenaga dokter didatangkan dari Rumah Sakit Umum Pusat Sardjito yakni Dokter Probo suseno 
seorang ahli kesehatan Lansia. Kerjasama ini tidak hanya didorong oleh karena faktor komersial tetapi juga atas kesadaran serta mempunyai komitmen dalam membangun kesehatan bagi lansia dan pra lansia, karenanya wajar apabila Pemerintah Kota harus mengkucurkan dana rata-rata 312 juta/tahun dalam memfasilitasi program Rumah Sehat Lansia. Mengingat kota Yogyakarta sebagai kota dengan jumlah penduduk lansia terbanyak, maka diharapkan inovasi rumah sehat lansia dapat bersinergi dalam menjangkau para lansia yang mengalami berbagai gangguan kesehatan. Adapun yang menjadi saran dalam penelitian kami mengenai inovasi rumah sehat lansia adalah sebagai berikut:

1. Agar pemerintah kota memberi perhatian dalam mengalokasikan dana untuk menambah jumlah unit rumah sehat lansia di tiap-tiap kecamatan sehingga dapat menjangkau para lansia di tiap-tiap daerah di kota Yogyakarta. Hal ini memang membutuhkan dana yang besar. Tetapi apabila dilakukan dengan komitmen bersama pasti akan terlaksana.

2. Memperhatikan jumlah tenaga medis dokter dan perawat yang menangani para lansia. Mengingat selama ini kunjungan dokter efektifnya hanya 2 kali dalam seminggu yakni hari rabu dan sabtu. Sehingga dengan jumlah dokter yang memadai maka jumlah kunjungan dokter dapat diperbanyak lagi bahkan diharapkan dapat melayani setiap hari mengingat jumlah pasien yang tidak sedikit.

3. Pemerintah kota Yogyakarta hendaknya memperhatikan fasilitas-fasilitas kesehatan mislanya peralatan medis, kamar dan tempat tidur pasien sehingga rumah sehat lansia dapat menampung pasien untuk menjalani rawat inap demi pelayanan kesehatan yang berkualitas.

4. Karena anggaran yang terbatas, kami menyarankan untuk mendirikan lembaga yang berfungsi mewadahi sumbangan dari inivestor maupun sukarelawan yang mau membantu menyumbangkan kekayaannya untuk membantu rumah sehat lansia, sebagai keberlanjutannya membuka rekening yang digunakan untuk menyimpan setiap sumbangan bagi para donatur. Sehingga kegiatan rumah sehat lansia dapat berjalan dengan lancar. 


\section{REFRENSI}

\section{Buku:}

Dwiyanto, Agus. 2008. Mewujudkan Good Governance Melalui Pelayanan Publik. Yogyakarta: Gadjah Mada University Press.

Hutasoit, C.S. 2011.Pelayanan Publik Teori dan Aplikasi.Jakarta: MagnaScript Publising.

Mathew J. Miles, dan A. Micheal Huberman. 1992. Analisis Data Kualitatif:Buku Sumber Tentang Metode Baru. Jakarta: UI Press.

Moleong, Lexy. 2011. Metode Penelitian Kualitatif.Bandung: PT. Remaja Rosdakarya.

\section{Jurnal:}

Chandra.2012.eksistensi proyek lansia. Diakses pada tanggal 3 Juli 2019 melalui http://ejournal.uajy.ac.id/1070/2/ITA12520.pdf

Harditya Bayu Kusuma. Inovasi Pelayanan Publik: Praktik Penyelenggaraan Otonomi Daerah.Jurnal Analisis Kebijakan.Volume 1 Nomor 1 Tahun 2016. Deputi Bidang Kajian Kebijakan Lembaga Administrasi Negara Republik Indonesia. hlm. 74-93. (lan.go.id. diakses tanggal 15 Juli 2017).

\section{Undang-Undang:}

Undang-Undang 36 Tahun 2009

Perwali Yogyakarta No 69 Tahun 2018

Undang-Undang Republik Indonesia Nomor 25 Tahun 2009 Tentang Pelayanan Publik.(https://www.setneg.go.id/index.php?option=com_perundangan\&id=2274\&task=det ail\&catid=1\&Itemid=42\&tahun=2009. 